\title{
Effect of implant design and bone density in primary stability
}

\author{
Nathalia Ferraz Oliscovicz'1, Antônio Carlos Shimano², Elcio Marcantonio Junior ${ }^{3}$, \\ César Penazzo Lepri ${ }^{1}$, Andréa Cândido dos Reis ${ }^{1}$
}

\author{
'Department of Dental Materials and Prosthodontics, School of Dentistry of Ribeirão Preto, University of São Paulo, Ribeirão Preto, SP, Brazil \\ ${ }^{2}$ Department of Biomechanics, Medicine and Rehabilitation of the Locomotor, School of Medicine of Ribeirão Preto, University of São Paulo, \\ Ribeirão Preto, SP, Brazil \\ ${ }^{3}$ Department of Diagnostic and Surgery, School of Dentistry of Araraquara, UNESP - Univ Estadual Paulista, Araraquara, SP, Brazil
}

\begin{abstract}
Aim: To evaluate the influence of the format and surface treatment of implants, as well as the substrate used in primary stability. Methods: Thirty-two Conexão ${ }^{\circledR}$ implants were used: 8 conical (CC) $(11.5 \times 3.5 \mathrm{~mm})$ and 24 cylindrical $(11.5 \times 3.75 \mathrm{~mm})-8$ external hexagon implants without surface treatment (MS), 8 external hexagon implants with double Porous treatment (MP), 8 internal hexagon implants with Porous treatment $(\mathrm{CA})$. They were inserted in Nacional ${ }^{\circledR}$ polyurethane in three densities (15, 20 and $40 \mathrm{PCF})$. The insertion torque (IT) (N.cm) was quantified using the digital Mackena ${ }^{\oplus}$ torque meter, and the pullout force (PF) (N) by means of axial traction force with a $200 \mathrm{~kg}$ load cell, performed in a Universal Test Machine $\left(\mathrm{Emic}^{\circledR} \mathrm{DL}\right.$ $10000)$ and the Tesc 3.13 software. Data were analyzed statistically by ANOVA and Tukey's test with a significance level of $5 \%$. Results: Difference was observed between groups $(p<0.05)$. Regarding the IT, MP and MS inserted to the substrate 4OPCF showed higher values with statistically significant difference with all interactions implants $x$ substrate; the 15 and 20PCF densities was not significant in all groups of implants. MP, MS, CC and CA did not differ significantly, even inserted in a lower density, where CC showed better IT compared with other densities. For PF, the best performance was the interaction implant CA x 40PCF substrate, showing a difference from the other implants inserted in all substrates. Conclusions: The higher bone density and cylindrical implants with surface treatment provides greater IT and PF.
\end{abstract}

Keywords: dental implants, biomechanics, bone substitutes, polyurethanes.

\section{Introduction}

Received for publication: March 23, 2013 Accepted: June 25, 2013

Correspondence to: Andréa Cândido dos Reis Avenida do Café, s/no ${ }^{\circ}$, CEP: 14040-904 Ribeirão Preto, SP, Brasil Phone: +551636023952

Fax: +551636330999 E-mail: andreare73@yahoo.com.br
The oral rehabilitation with implants has high success rates because of the process of osseointegration. For its occurrence, the primary stability must be respected $^{1-5}$, defined as lack of mobility in the surgical stage. Biological and mechanical factors, influenced by surgical technique, bone quality and quantity, and implant's geometry ${ }^{3,6}$, are the key factors that define the primary stability and then, the success of osseointegration.

Bone density is one of the most important parameters for the long-term success of dental implants. To observe the influence of this factor on primary stability in in vitro analysis, composed polyurethane substrates are frequently used ${ }^{3-6}$, which is used as synthetic bone substitutes of the human bone and is used in studies of 
implants. The human bones have high variability ${ }^{7}$ and characteristics that may influence the reliability and validity of measurements, such as fenestrations ${ }^{1}$, which makes necessary a very large sample to obtain a satisfactory significance in statistical comparisons. This is a hindrance to studies due to problems of availability, handling, preparation and preservation of natural bones ${ }^{7}$.

The knowledge of the bone density is essential for the dentist to come up with the best possible surgery plan, and selects the appropriate implant design to obtain primary stability. The development of new implant designs, surface treatments and a better understanding about bone biology have led to constant changings in implantodonty ${ }^{8}$. The large number of models available in the market or the absence of manufacturer's clarification the effectiveness of the different models leave the surgeon with doubts and raise questions about design features. Implant design should be widely studied by researchers in order to increase the surface area in contact with the bone, consequently the osseointegration, bone anchorage and load distribution ${ }^{9-10}$.

Therefore, the stability is a primary requirement to determine the type of prosthetic treatment that will be started, which should be evaluated prior to application of force ${ }^{11}$. It is important the determination of a safe and practical method to detect the occurrence the primary stability. The numerical value of the initial stability can be provided for clinical instruments such as Periotest and Osstell, and can be translated as the insertion torque value measured during the final seating of the implant in the recipient bed, which provides information about the quality of local bone, it can easily be obtained with the aid of a surgical wrench.

In addition to the clinical methods used for measuring primary stability, there are mechanical tests that analyze the resistance to movement of the implants and may be related to the physical and chemical properties of the screw. The pullout strength implant, widely studied in the Medical Orthopedics, is multifactorial and is related to bone mineral density, with the implant design and surgical technique, and it is proportional to thread surface in contact with the bone tissue, to avoid its releasing and classifies it as a property of stability of the screw ${ }^{12}$. Nowadays, there are a few available reports in the literature about the tensile strength of dental implants, which it could certainly contribute to the study of primary stability and its relation to the design of implants, where its proper selection is imperative to decrease the magnitude, quantity, and type of loads imposed on the implant / bone interface ${ }^{13}$.

It is believed that tensile tests associated with the insertion torque may add knowledge regarding to the primary stability of implants, since it can quantify the maximum force required for destabilization of the implant in bone. These studies are important for researchers to engage in search of new materials, devices and designs of screw that can fill the gaps offered by the limitations of the surgical technique and quality and quantity of bone site receiving the implant.

The aim of this study was to evaluate the primary stability of dental implants through performance tests to increase the knowledge of designs and bone densities, which allow increasing the primary stability due to a variety of available models with the progress and development in dental industry.

\section{Material and methods}

\section{Substrates for implant placement}

For this study was used National ${ }^{\circledR}$ polyurethane (Nacional Ossos, Jaú, São Paulo, Brazil) in three different densities: 40, $20,15 \mathrm{PCF}$ or $0.64 \mathrm{~g} / \mathrm{cm}^{3}, 0.32 \mathrm{~g} / \mathrm{cm}^{3}$ and $0.24 \mathrm{~g} / \mathrm{cm}^{3}$, respectively. The substrates had a rectangular shape with dimensions of 4.2 of height, $17.8 \mathrm{~cm}$ wide and $6.5 \mathrm{~cm}$ length, so that they make feasible their uses in mechanical testing; and homogeneous density, which allowed a standard analysis for the variable type of bone ${ }^{7}$ and emphasized the comparison between the screws in relation to the shape on the surface treatment.

\section{Implants}

In the studies were used 32 implants Conexão ${ }^{\circledR}$ (Conexão, Jau, Sao Paulo, Brazil) divided in four groups according to the their designs $(n=8)$ : cylindrical - Master Porous (external hexagon with double porous treatment of surface), Master Screw (external hexagon without surface treatment), Master Conect AR (internal hexagon with porous surface treatment); and conical - Master Conect Conico (external hexagon without surface treatment). The cylindrical implants had $3.75 \mathrm{~mm}$ diameter, while the conical implants had $3.5 \mathrm{~mm}$. The length was $11.5 \mathrm{~mm}$ for all types of implants. (Figure 1)

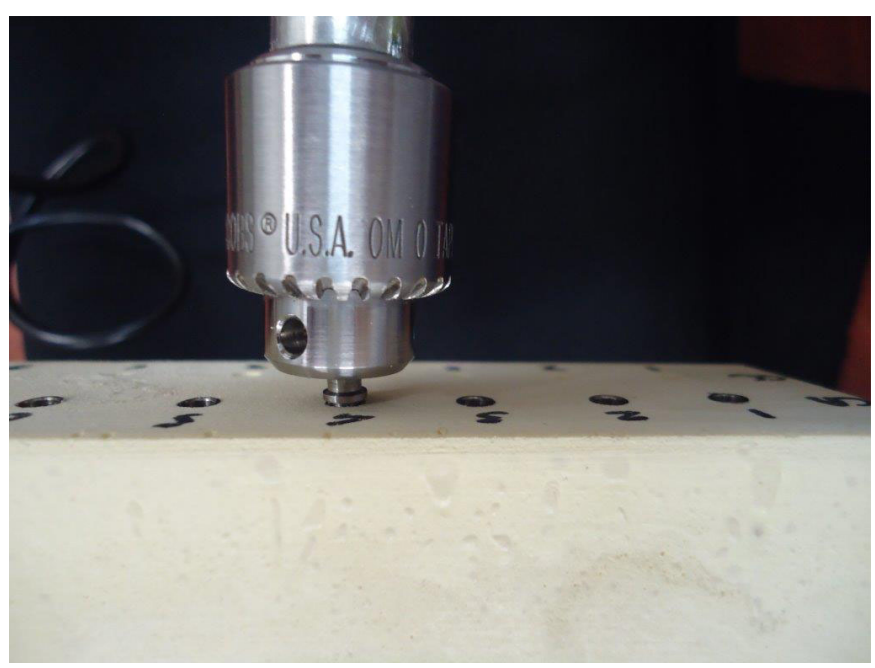

Fig. 1 - Insertion torque of implant inserted in the polyurethane

\section{Installation of the implants}

In each sample of polyurethane were installed two groups of implants, in a centralized way with respect to the side of the substrate. The preparation of hole in the polyurethane substrate started with a distance of $7 \mathrm{~mm}$ from the marking of the adjacent implant in order to prevent that the tests performed in an implant could interfere in the quality 
of the substrate. The holes were carried out following the sequence of cutters provided by the manufacturer $\left(\right.$ Conexão $\left.{ }^{\circledR}\right)$. After each drilling and hole preparation, the implant was installed in its place with the supporting of a surgical torque wrench, and then it was measured the maximum insertion torque and then it was subjected to a tensile force until the pullout strength of the polyurethane of respective density. After their analysis, the implants were removed and installed in another density of polyurethane.

\section{Analysis of Insertion Torque}

The primary stability was measured by insertion torque with a support of digital wrench Mackena ${ }^{\hat{a}}$ (Mackena Indústria e Comércio Ltda., São Paulo, São Paulo, Brazil), model MK-2001; capable of torque measuring up to 120 N.cm. This was coupled to the mount-implants of the respective shapes of the external hexagon implants (cylindrical or conical), and to device developed for the connection with internal hexagon implants; both screwed on implants (Figure 1) The value was measured in each turn of the screw, being considered the maximum value obtained, the maximum insertion torque. The torque wrench provided a numerical value which was passed to a formula obtained after calibration of the device, converting the value to N.cm unit: $y=0.0449 x-0.7907$, so $y=$ value in N.cm, $x=$ value with reading on the wrench.

\section{Analysis of Pullout Strength}

The analysis of pullout strength is used as a method to compare different shapes of metal screws according to the American Society for Testing and Materials ${ }^{14}$.

To check the maximum pullout strength were used the same devices screwed in internal hexagon implants, and the respective mount-implants of conical and cylindrical external hexagon implants, for connection of the implant to the mobile basis of the testing machine. The substrate made of polyurethane with the implant inserted was located in the lower part of a steel lump with a hole in the center. The accessory developed and the mount - implants were connected to the implant by threads present in two structures and after that connected to the mobile basis from machine through a pin, being attached to a piece that served for adaptation in the load cell $(200 \mathrm{~kg})$ of the universal testing machine $\left(\mathrm{Emic}^{\circledR}\right.$; Emic Equipamentos e Sistemas de Ensaios Ltda., São José dos Pinhais, PR, Brazil) model DL-10000N. Each implant was submitted to the pullout testing by axial force a with a constant velocity of $2 \mathrm{~mm} / \mathrm{min}$. (Figure 2) Through the Tesc Software 1.13 Program was carried out the analysis of results obtained during the mechanics tests. It was evaluated the mechanical properties of tensile ultimate strength.

\section{Statistical Analysis}

The data were analyzed for their distribution and homogeneities. As the distribution was normal (KolmogorovSmirnov) and homogeneous (test of homogeneity of variances - Levene) two-way ANOVA and Tukey's test were applied with a significance level of $5 \%$.

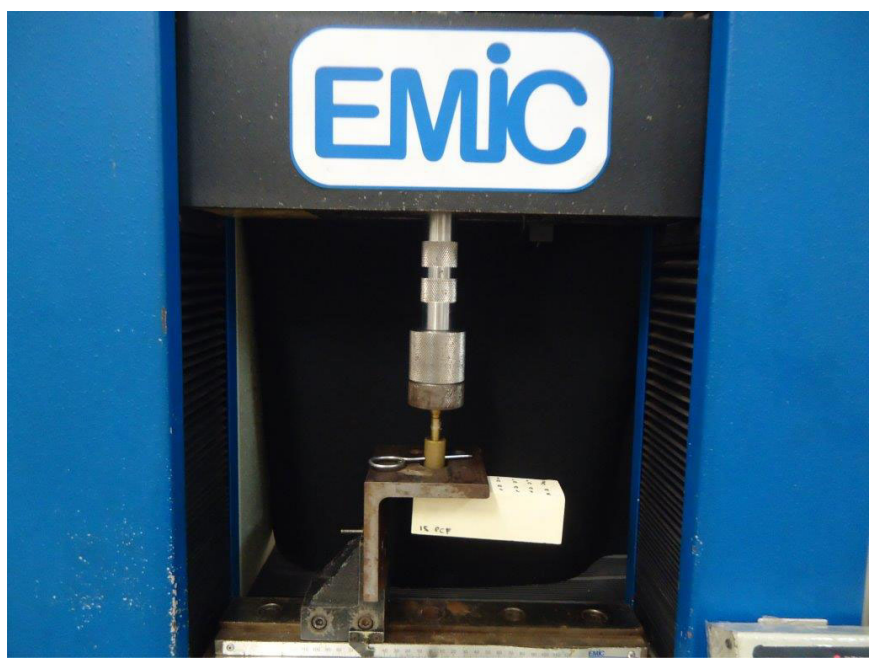

Fig. 2 - Pullout test of implant inserted in the polyurethane

\section{Results}

\section{Analysis of Insertion Torque}

Regarding the IT, MP and MS inserted to the substrate 40PCF showed higher values with statistically significant difference with all interactions implants $\mathrm{x}$ substrate; the densities of 15 and 20PCF was not statistically significant in all groups of implants. MP, MS, CC and CA did not differ significantly, even inserted in a lower density.

Master Porous and Master Screw implants inserted into polyurethane of $40 \mathrm{PCF}$ showed the highest values of insertion torque $-31.1 \mathrm{Ncm}$ and $24.4 \mathrm{Ncm}$, respectively, without statistically significant difference; but there were differences with the others $(p<0.05)$. However, when placed in substrates with density of $20 \mathrm{PCF}$ and $15 \mathrm{PCF}$, did not show statistical difference. The CC and CA implants had no statistical difference inserted into polyurethane of any densities. In the polyurethane of $15 \mathrm{PCF}$, there was no statistically significant difference among all types of implants, which were also similar to the $\mathrm{CC}$ implants inserted into the substrate of 20 PCF. At the density of 20 PCF, CA had the greatest results and was different of $\mathrm{CC}$ implants $(\mathrm{p}<0.05)$. CC implants showed the lowest results in the polyurethane of 20 and $40 \mathrm{PCF}$, but in a lower density $(15 \mathrm{PCF})$ the results were statistically equals to the other groups $(p>0.05)$ (Figure 3$)$.

\section{Analysis of Pullout Strength}

The implants inserted into the polyurethane of $40 \mathrm{PCF}$ showed the highest results of pullout strength and statistical difference $(p<0.05)$ with all implants placed in the substrates of 20 and 15 PCF. Among them, the CA implants had the greatest results - $1463.21 \mathrm{~N}$ with statistically significant difference from all other types of implants $(p<0.05)$, which were similar to each other. In the polyurethane of $20 \mathrm{PCF}$, the Master Porous and Master Screw implants were statistically different from the other types $(\mathrm{p}<0,05)$, but were equal to the same models on the polyurethane of 15 PCF. The CC implants did not show statistically significant difference when 


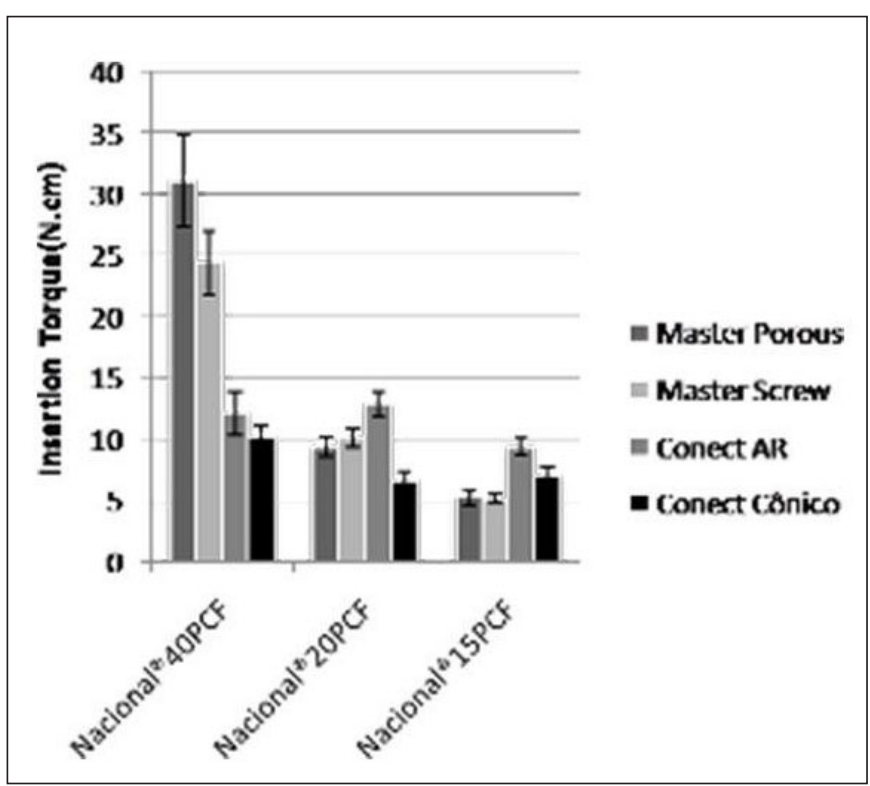

Fig. 3 - Insertion torque of implant Master Porous, Master Screw, Conect AR and Conect Cônico inserted in the polyurethane of 15, 20 and 40 PCF.

inserted into the polyurethane of 20 and 15 PCF $(p<0.05)$. Conect AR implant in polyurethane of 15 PCF did not have statistical difference with the same design, but significant difference was found when the implant was inserted into the substrate of 20 PCF density (Figure 4).

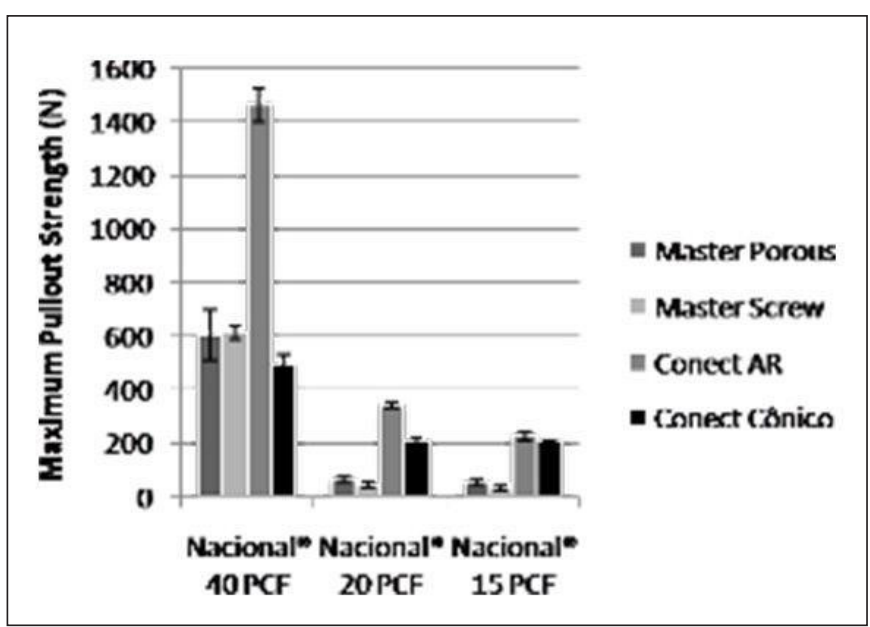

Fig. 4 - Pullout test of implants Master Porous, Master Screw, Conect Ar and Conect Conico inserted in the polyurethane of 15,20 and 40 PCF.

\section{Discussion}

The primary stability is essential factor for achievement of osseointegration ${ }^{1,3,6}$ by preventing the formation of connective tissue in the implant / bone interface and allow the bone formation ${ }^{6}$ which allows appropriate distribution of masticatory functional loads ${ }^{3,6}$. Important strategies, such as increasing the quantity and quality of bone and appropriate implant designs have been investigated in order to provide the initial stability and achieve a greater predictability of osseointegration, particularly in bones of low density ${ }^{6}$, where an adequate primary anchorage is hardly achieved.

Many methods have been proposed to measure the primary stability, such as the Periotest, the resonant frequency and insertion torque, non-invasive tools which provide numerical values of the stability of implant through the measurement of stiffness in the bone/implant interface during or after installation ${ }^{15}$. The insertion torque is the angular moment of force required that the screw advances the screw thread inside the mounting hardware ${ }^{16}$, and provides fast and objective information about the quality of local bone ${ }^{6-15}$ and the primary stability at surgery ${ }^{6}$. According to Ottoni et al. ${ }^{17}$, the risk of loss of implants submitted to immediate load is reduced until $20 \%$ for each growth of $9.8 \mathrm{~N} . \mathrm{cm}$ in the insertion torque, which demonstrates the relation of these values have to do with the primary stability. The insertion torque seems to be one of the most efficient techniques and has fewer contraindications in measuring the primary stability ${ }^{3}$, so our study has selected this method to quantify this property.

Regarding the insertion torque the cylindrical implants with external hexagon of double surface treatment and without treatment (Master Porous and Master Screw), inserted into the polyurethane of 40 PCF, had higher values of all other types and other densities of substrate, demonstrating that cylindrical implants had a better performance. The comparison among different designs of implants was examined in several studies and noticed that conical implants have a higher insertion torque than cylindrical implants ${ }^{3,9}$. However, checking the resonant frequency, Browers et al. ${ }^{1}$ found higher values for the cylindrical implants compared with the conical, that confirms our results.

Statistically, the Master Porous and Master Screw implants were equals in the insertion torque of all densities and shows that the presence of surface treatment did not influence the results, despite having selected the use of machined implants (Master Screw and Conect Cônico) as negative control, due to better biomechanical characteristics of the treated implants, which its surface roughness, theoretically promotes a larger area of bone-implant contact ${ }^{18-19}$. So, our results contradict studies that found a higher primary stability at treated implants ${ }^{8,19-20}$. However, our results can be explained by Cunha et al. ${ }^{21}$, who concluded that the design is more important than the surface for primary stability, when verified that the stability of machined implants was the highest of those treated.

On these cylindrical implants with external hexagonal, the insertion in the highest density provided the highest values of insertion torque, but placed at densities of 20 and 15 PCF there was no difference between them, what shows that the density just influenced when was very high.

Both conical implants (Conect Cônico) and in the internal hexagon implants (Conect AR), at any density results of insertion torque were statistically identical, so there was no influence of density on these types of implants. These screw designs inserted into the polyurethane of $40 \mathrm{PCF}$ showed equal values statistically to the Master Screw and Master Porous in polyurethane of PCF 20, pointing out that these cylindrical implants and external hexagon had a better performance. This is repeated in the conical implants at 20 PCF that had equal values of insertion torque to the Master 
Screw and Master Porous in the substrate of PCF 15, showing again the best performance of these implants that shows higher values even in a lower density.

In the density of 15 PCF there was no statistically significant difference on insertion torque between the shapes of the implants, seeming that there is no influence in the shape in the low density. In the density of $20 \mathrm{PCF}$, only the internal hexagonal implants, that had the highest values of torque, presented statistically different from the others. The conical implant had better performance of insertion torque when inserted into the lower density in comparison with their results in the other two densities, however it was statistically equal to the cylindrical implants.

In addition to the methods already proposed to assess the initial fixation of implants, some mechanical tests have been suggested, such as pullout strength, widely used and researched in studies of orthopedic implants ${ }^{12,22}$, and dental implants for measuring osseointegration by bonding strength of bone-implant ${ }^{23}$. The pullout strength is influenced by geometric features of the screw, such as shape, diameter and shape of the threads. In addition to the geometrical characteristics, surgical technique and substrate, especially with respect of density, also have influence about results ${ }^{12}$. Despite the pullout test be static axial force application, these factors are also related to primary stability, so our work has proposed this method to compare different screws, as well its form as surface treatment.

When analyzing the maximum pullout strength, there was statistical difference among the groups of implants inserted in 40, 20 and 15 PCF; therefore the density of the substrate influences the stability of the screw. The values of cylindrical internal hexagon implants with treatment placed in the highest density (40 PCF) presented the highest and with statistically difference with all others, but among other implant designs (conical and cylindrical external hexagon, with or without double treatment) in the same material, there was no difference, showing that the shape and treatment did not influence, and probably the type of connection influenced. In the polyurethane of 20 PCF the cylindrical implants and internal hexagon showed once more higher values of pullout strength, and they were statistically equals to those inserted into $15 \mathrm{PCF}$. They were also equals to the conical in $20 \mathrm{PCF}$, which they did not differ when inserted into the polyurethane of $15 \mathrm{PCF}$, showing that the lowest density values do not interfere in the results of the conical and internal hexagon implants. The same happened with cylindrical implants and external hexagon with double treatment and without it, where there wasn't difference to them as much 20 as 15 PCF, and besides, these types of designs there were not difference, showing that the existence of treatment did not influence the maximum pullout strength.

Generally, cylindrical implants showed a better performance in pullout strength than the conical ones, in contrast to some studies that pointed out that conical screws had higher values than the cylindrical ones, both in insertion torque and pullout resistance ${ }^{22}$, due to the progressive increase of the diameter to get promotes the compression of the material around them ${ }^{12}$. However, the fact of the connection of the implants be internal hexagon, these procedure may have influenced on these superior strength results; and in the densities of 20 and 15 PCF, these conical implants had larger and statistically different results, from that cylindrical implants with external hexagon. Moreover, the conical implants had a smaller diameter than the cylindrical ones, due to the availability of the company; and it can have influenced the values of insertion torque and pullout strength as well as the study of Lill et al. ${ }^{24}$, that showed the screws with conical design may present inferior mechanical properties when compared to machine screws in different sizes.

According to the methodology and results, considering the limitations of this study, the surface treatment of implants did not influence the analysis of insertion torque and maximum pullout strength; cylindrical implants showed better performance on primary stability compared to the tapered implants in the utilized analysis; and the highest density of the substrate (40 PCF) influenced positively the results of primary stability of dental implants analyzed.

The relationship between primary stability and implant design presents different results, because studies are done using implants with different diameters, lengths and designs. Additionally, for some authors, the primary stability is more affected by the quantity and quality of the bone than the design of the implant ${ }^{25}$, as well as our study; and thus, the differences found in the literature may be based in the use of different substrates, synthetic or naturals; or even though with the use of dried bones that have up to $10 \%$ of the increase of elasticity modulus in comparison to the fresh bone ${ }^{1}$ what influences the stiffness of the bone-implant interface. This study examined only the mechanical aspects of the effect of design and surface treatment over the primary stability of dental implants. Biological factors, as individual characteristics and local variations of the human bone, as well as modifications in surgical technique to increase the anchoring of implants, are influential in the primary stability in a clinical situation.

Currently, there are several commercial brands of implants that vary in their shape, size, diameter, surface treatment, spacing of the coils, presence and extension of self-drilling region of implants, and prosthetic connections. The purpose of these modifications is to provide an implant that increases and improves the biological contact of the bone- implant interface, and thus promote a fast osseointegration, a better distribution of stress to the receiver bone bed and greater primary stability ${ }^{10}$. It should be reminded that the correlation between primary stability and pullout strength is a biomechanical suggestion. Thus, the higher stability of the screw in the inner bone suggests that the pullout strength is greater and, according to Kim et al. ${ }^{26}$, this property can be used to test the mechanical stability of implants.

\section{Acknowledgements}

The authors would like to thank Luiz Antônio Pitangui, of Dentscler Indústria de Aparelhos Odontológicos Ltda, for providing us with the motor for implants placement. 


\section{References}

1. Brouwers JEIG, Lobbezoo F, Visscher CM, Wismeijer D, Naeije M. Reliability and validity of the instrumental assessment of implant stability in dry human mandibles. J Oral Rehabil. 2009; 36: 279-83.

2. Çehreli MC, Kökat AM, Comert A, Akkocaoðlu M, Tekdemir I, Akça K. Implant stability and bone density: assessment of correlation in fresh cadavers using conventional and osteotome implant sockets. Clin Oral Implants Res. 2009; 20: 1163-9.

3. Chong L, Khocht A, Suzuki JB, Gaughan J. Effect of Implant Design on Initial Stability of Tapered Implants. J Oral Implantol. 2009; 35: 130-5.

4. Kahraman S, Bal BT, Asar NV, Turkyilmaz I, Tözüm TF. Clinical study on the insertion torque and wireless resonance frequency analysis in the assessment of torque capacity and stability of self-tapping dental implants. J Oral Rehabil. 2009; 36: 755-61.

5. Turkyilmaz I \& Mcglumphy EA. Influence of bone density on implant stability parameters and implant success: a retrospective clinical study. BMC Oral Health. 2008; 8: 1-8.

6. Tabassum A, Meijer GJ, Wolke JGC, Jansen JA. Influence of surgical technique and surface roughness on the primary stability of an implant in artificial bone with different cortical thickness: a laboratory study. Clin Oral Implants Res. 2010; 21:213-20.

7. Cristofolini L, Viceconti M. Mechanical validation of whole composite tibia models. J Biomech. 2000; 33: 279-88.

8. Martínez-González JM, García-Sabán F, Ferrándiz-Bernal J, GonzaloLafuente JC, Cano-Sánchez J, Barona-Dorado C. Removal torque and physico-chemical characteristics of dental implants etched with hydrofluoric and nitric acid. An experimental study in Beagle dogs. Med Oral Patol Oral Cir Bucal. 2006; 11: E281-5.

9. O'Sullivan D, Sennerby L, Meredith N. Measurements comparing the initial stability of five designs of dental implants: a human cadaver study. Clin Implant Dent Relat Res. 2000; 2: 85-92.

10. Carvalho BM, Pellizzer EP, Moraes SLD, Falcón-Antenuccil RM, Júnior JSF Surface treatments in dental implants. Rev Cir Traumatol Bucomaxilofac. 2009; 9: 123-30.

11. Morton D, Jaffin R, Weber H-P. Immediate restoration and loading of dental implants: Clinical considerations and protocols. In: Int J Oral Maxillofac Implants. 2004; 19: 103-8.

12. Inceoglu S, Ferrara L, McLain RF. Pedicle screw fixation strength: pullout versus insertional torque. Spine J. 2004; 4: 513-8.

13. Astrand P, Engquist B, Dahlgren S, Engquist E, Feldmann H, Gröndahl K. Astra Tech and Branemark system implants: a prospective 5-year comparative study- results after one year. Clin Implant Dent Relat Res. 1999; 1: 17-26.

14. American Society for Testing Materials. [cited 2011 Jan] Available from: http://www.astm.org.

15. Turkyilmaz I, Mcglumphy EA. Influence of bone density on implant stability parameters and implant success: a retrospective clinical study. BMC Oral Health. 2008; 8: 1-8.

16. Daftari TK, Horton WC, Hutton WC. Correlations between screw hole preparation, torque of insertion, and pullout strength for spinal screws. J Spinal Disord. 1994; 7:139-45.

17. Ottoni JMP, Oliveira ZFL, Mansini R, Cabral AM. Correlation between placement torque and survival of single-tooth implants. Int J Oral Maxillofac Implants. 2005; 20: 769-76

18. Barros RRM, Novaes Jr. AB, Papalexiou V, Souza VLS, Taba Jr. M, Palioto DB et al. Effect of biofunctionalized implant surface on osseointegration - a histomorphometric study in dogs. Braz Dent J. 2009; 20: 91-8.

19. Klokkevold PR, Nishimura RD, Adachi MA, Caputo A. Osseointegration enhanced by chemical etching of the titanium surface. A torque removal study in the rabbit. Clin Oral Implants Res. 1997; 8: 442-7

20. Sakoh J, Wahlmann U, Stender E, Al-Nawas B, Wagner W. Primary Stability of a Conical Implant and a Hybrid,Cylindric Screw-Type Implant In Vitro. Int J Oral Maxillofac Implants. 2006; 21: 560-6.
21. Cunha HA, Francischone CE, Nary Filho H, Oliveira RCG. A comparisson between cutting torque and resonance frequency in the assessmen of primary stability and final torque capacity of standard TiUnite single-tooth implants under immediate loading. Int J Oral Maxillofac Implants. 2004; 19: 578-85.

22. Zamarioli A, Simões PA, Shimano AC, Defino HLA. Insertion torque and pullout strength of vertebral screws with cylindrical and conic core. Rev Bras Ortop. 2008; 43: 452-9.

23. Ban S, Maruno S, Arimoto N, Harada A, Hasegawa J. Effect of electrochemically deposited apatite coating on bonding of bone to the HA-GTi composite and titanium. J Biomed Mater Res. 1997; 36: 9-15.

24. Lill CA, Schlegel U, Wahl D, Schneider E. Comparison of the in vitro holding strengths of conical and cylindrical pedicle screws in a fully inserted setting and backed out 180 degrees. J Spinal Disord. 2000; 13: 259-66.

25. Rozé J, Babu S, Saffarzadeh A, Gayet-Delacroix M, Hoornaert A, Layrolle P.Correlating implant stability to bone structure.Clin Oral Impl Res. 2009; 20: 1140-5.

26. Kim JW, Baek SH, Kim TW, Chang YI. Comparison of stability between cylindrical and conical type mini-implants. Angle Orthod. 2008; 78: 692-8. 